\title{
Intersegmental Arterial Communication between the Medial and Left Lateral Segments of the Liver
}

\author{
Akihiro Cho $^{a}$ Hisashi Gunji $^{a}$ Naoto Koike ${ }^{b}$ Souichi Narumoto ${ }^{c}$ \\ Takehide Asano $^{a}$ Hiroshi Yamamoto $^{a}$ Osamu Kainuma ${ }^{a}$ Munemasa Ryu ${ }^{a}$ \\ Chisato Mori $^{d}$ Gen Murakami $^{\mathrm{e}}$ Shinichi Okazumi ${ }^{\mathrm{f}}$ Takenori Ochiai $^{\mathrm{f}}$ \\ ${ }^{a}$ Department of Gastroenterological Surgery, Chiba Cancer Center Hospital, Chiba, ${ }^{b}$ Department of Surgery, \\ Seirei Sakura Citizen Hospital, Chiba, ' Department of Hepato-Pancreato-Biliary Surgery, Shizuoka Cancer Center \\ Hospital, Chiba, dDepartment of Bioenvironmental Medicine, Chiba University, Chiba, 'Department of Anatomy, \\ Sapporo Medical University School of Medicine, Sapporo, and fDepartment of Academic Surgery, Chiba University \\ Graduate School of Medicine, Chiba, Japan
}

\section{Key Words}

Hilar cholangiocarcinoma $\cdot$ Medial segment $\cdot$ Left lateral segment $\cdot$ Umbilical plate $\cdot$ Arterial communication

\begin{abstract}
Background/Aims: Although the interlobar arterial collateral of the liver has been thoroughly analyzed, few reports have described the intersegmental arterial collateral between the medial and left lateral segments. Methods: The hepatic arterial system of the left liver was evaluated using 12 latex resin cast specimens in which latex resin was injected into the left hepatic artery after ligation of the right hepatic artery. Results: In all 12 livers, an intersegmental collateral between the medial and left lateral segments was detected. These collaterals were extrahepatically located in the umbilical plate and gave rise to branches traveling to the bile duct of the left liver. Conclusions: The present study showed that the communicating arcade between the middle and left lateral hepatic arteries was consistently present in the umbilical plate and played an important role not only in the intersegmental arterial collateral system of the left liver but also in the blood supply to the bile ducts.
\end{abstract}

Copyright $\odot 2007$ S. Karger AG, Basel

\section{Introduction}

Surgical en-bloc resection has contributed to improved long-term survival in patients with biliary tract malignancies [1-7]. However, the complex anatomy of the hepatic hilum still causes difficulties with curative resection. To safely and satisfactorily excise the hepatic hilum, the anatomy of hilar vessels must be understood [8]. In resection for hilar cholangiocarcinoma, resection of the right side of the liver was more commonly observed than resection of the left side, because the left hepatic duct has a long extrahepatic course and tumor invasion of the right hepatic artery is more likely [9-11]. The purpose of the present study was to evaluate the hepatic arterial system of the left side of the liver, using acrylic corrosion casts.

\section{Materials and Methods}

Twelve adult livers from fresh cadavers (3-12 $\mathrm{h}$ after death) with no lesions at the hepatic hilum were obtained from the Department of Anatomy, Sapporo Medical University School of Medicine, Sapporo, Japan, and were used for preparation of cast specimens. After ligation of the right hepatic artery near its ori-

\section{KARGER}

Fax +4161306 1234 E-Mail karger@karger.ch www.karger.com

\section{Akihiro Cho}

Department of Gastroenterological Surgery, Chiba Cancer Center Hospital 666-2 Nitonachou, Chuouku

Chiba 260-8717 (Japan)

Tel. +81 43264 5431, Fax +81 43262 8680, E-Mail acho@chiba-cc.jp 


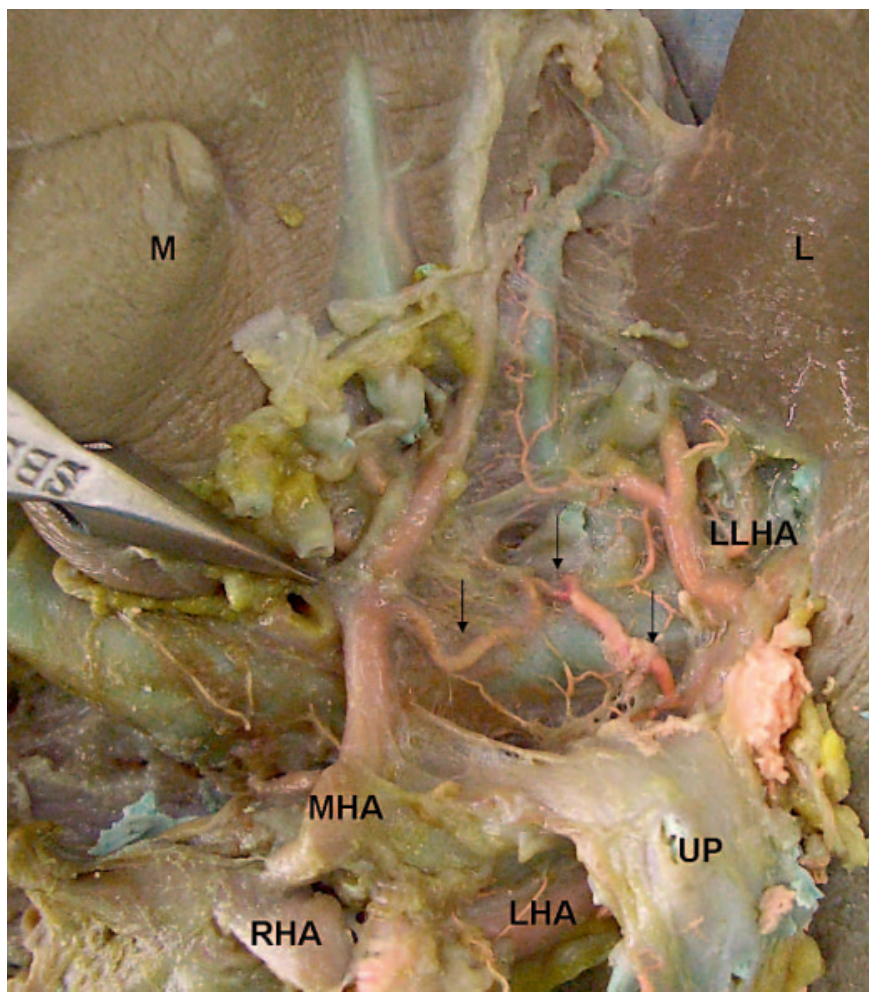

Fig. 1. Photographic representation of the left hepatic arterial system in the communicating pattern. After ligation of the right hepatic artery, red-colored resin was injected into the left hepatic artery. The biliary system was filled with green-colored resin. The umbilical portion of the portal vein (UP) was removed. Red-colored resin filled the middle hepatic artery via the intersegmental collateral (arrows) between the medial segment (M) and the left lateral segment $(\mathrm{L})$, which formed the arterial network and gave rise to branches traveling to the bile duct.

gin, approximately $20 \mathrm{ml}$ of water-soluble absolute latex resin (Neoplen Latex 601-A; DuPont Dow Elastomers, Tokyo, Japan) was injected into the left hepatic artery until the subcapsular vessels on the liver surface were visualized. After latex injection, the fresh cadaveric livers were fixed in $10 \%$ formalin solution. They were then dissected at least 7 days following fixation. The porta hepatis was carefully dissected to visualize the middle and left hepatic arteries and their relationship.

\section{Results}

All twelve corrosion casts were of sufficiently good quality to be used to analyze the detailed hepatic arterial anatomy. Seven livers had a conventional proper hepatic artery. The middle hepatic artery arose from the left hepatic artery in five of these livers and from the right hepatic artery in the other two. In three other livers, the

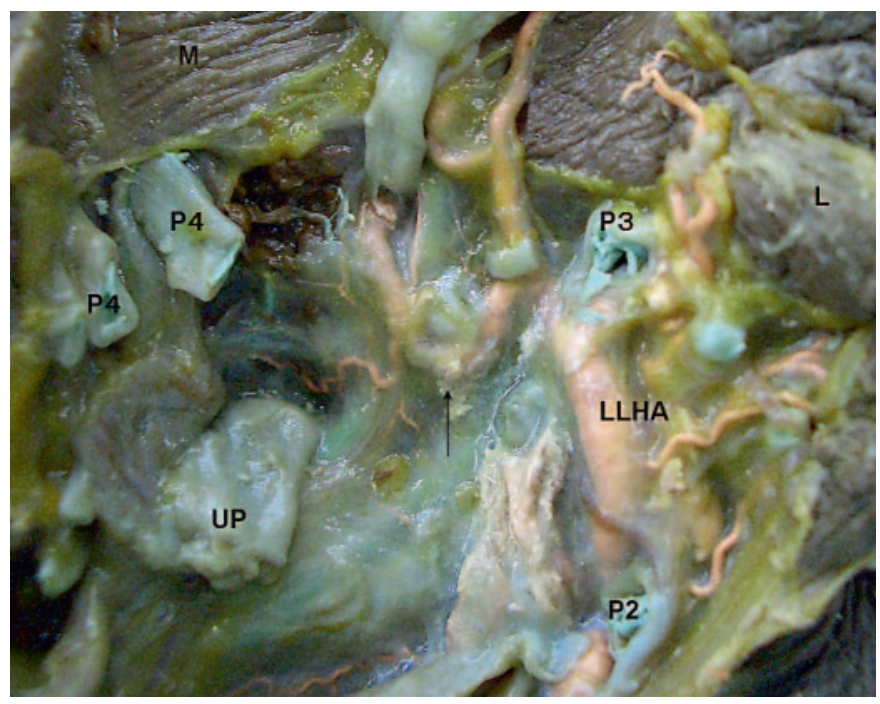

Fig. 2. The left lateral hepatic artery gave rise to a branch (arrow) that crossed the umbilical fissure and nourished the liver parenchyma of the medial segment without communicating with the middle hepatic artery. $\mathrm{P} 4=$ The portal vein of segment $4 ; \mathrm{P} 3=$ the portal vein of segment $3 ; \mathrm{P} 2=$ the portal vein of segment 2 .

right hepatic artery arose from the superior mesenteric artery and the middle hepatic artery arose from the left hepatic artery. In the remaining two livers, the left hepatic artery arose from the left gastric artery and the middle hepatic artery arose from the right hepatic artery. In all 12 casts examined, a communicating arcade between the middle and the left lateral hepatic arteries was observed. The communicating arcade was extrahepatically located in the umbilical plate, consistently crossed the umbilical portion cranially, and gave rise to branches to the bile duct (fig. 1). In the three livers in which the middle hepatic artery arose from the left hepatic artery, the left lateral hepatic artery forked off into branches that crossed the umbilical portion and nourished the liver parenchyma of the medial segment without communicating with the middle hepatic artery (fig. 2).

\section{Discussion}

The interlobar arterial collateral of the liver has been thoroughly analyzed using both anatomical $[12,13]$ and radiological studies [14-16]. Our previous study showed that the communicating arcade between the right and left hepatic arteries was consistently present in the hilar plate and played an important role not only in the interlobar 
arterial collateral system of the liver but also in the blood supply to the hilar bile ducts [17]. In contrast, few reports have described the intersegmental arterial collateral between the medial and left lateral segments. In the present study, the intersegmental arterial collaterals between the middle and left lateral hepatic arteries were clearly visualized in all livers examined. These collaterals were found to be extrahepatically located in the umbilical plate and gave off a few thin branches to the bile ducts. Some previous studies described that the arterial collaterals between the right and left hepatic arteries nourished the hilar bile ducts and formed the arterial network in the hilar plate $[12,13,17,18]$. We believe that the whole plate system may have an arterial network that has an important function as a collateral system between segments of the liver. Whether the middle hepatic artery should be preserved in the right side resection for cholangiocarcinoma has been a matter of controversy. The present study showed that the intersegmental arterial collaterals between the middle and left lateral hepatic arteries exists in all livers. We suppose that the development of collateral blood flow to the medial segment can be expected if the middle hepatic artery is divided. We consider that the middle hepatic artery should not be preserved if the middle hepatic artery is located close to the hilar cholangiocarcinoma. In conclusion, although our study was limited by the small size of the study group and the fact that no actual gold standard existed for the findings and comparisons of radiological and surgical findings, we consider recognition of this vascular anatomy to be clinically important for performing liver resection for hilar cholangiocarcinoma.

\section{References}

1 Blumgart LH, Hadjis NS, Benjamin IS, Beazley R: Surgical approaches to cholangiocarcinoma at confluence of hepatic duct. Lancet 1984;i:66-70

-2 Iwasaki Y, Okamura T, Ozaki A, Todoroki T, Takase Y, Ohara K, Nishimura A, Otsu H: Surgical treatment for carcinoma at the confluence of the major hepatic ducts. Surg Gynecol Obstet 1986;162:457-464.

3 Mizumoto R, Kawarada Y, Suzuki H: Surgical treatment of hilar carcinoma of the bile duct. Surg Gynecol Obstet 1986;162:153158.

4 Nimura Y, Hayakawa N, Kamiya J, Kondo S, Shionoya S: Hepatic segmentectomy with caudate lobe resection for bile duct carcinoma of the hepatic hilus. World J Surg 1990; 14:535-544.

5 Nimura Y, Kamiya J, Nagino M, Kanai M, Uesaka K, Kondo S, Hayakawa N: Aggressive surgical treatment of hilar cholangiocarcinoma. J Hepatobiliary Pancreat Surg 1998;5: $52-61$.

6 Hemming AW, Reed AI, Fujita S, Foley DP, Howard RJ: Surgical management of hilar cholangiocarcinoma. Ann Surg 2005;241: 693-702.
7 Otto G, Romaneehsen B, Hoppe-Lotichius M, Bittinger F: Hilar cholangiocarcinoma: resectability and radicality after routine diagnostic imaging. Hepatobiliary Pancreat Surg 2004;11:310-318.

8 Cho A, Okazumi S, Yoshinaga Y, Ishikawa Y, Ryu M, Ochiai T: Relationship between left biliary duct system and left portal vein: evaluation with three-dimensional portocholangiography. Radiology 2003;228:246-250.

-9 Bengmark S, Ekberg H, Evander A, KlofverStahl B, Tranberg KG: Major liver resection for hilar cholangiocarcinoma. Ann Surg 1988;207:120-125.

10 Tashiro S, Tsuji T, Kanemitsu K, Kamimoto Y, Hiraoka T, Miyauchi Y: Prolongation of survival for carcinoma at the hepatic duct confluence. Surgery 1991;113:270-278.

11 Cho A, Ryu M, Kinoshita T, Kawano N, Konishi M, Miyazawa Y, Okazumi S, Ochiai T: Radiological anatomy of the medial segmental bile duct of the liver assessed by CT cholangiography. Hepatogastroenterology 2003; 50:945-948.

12 Stapleton GN, Hickman R, Terblanche J: Blood supply of the right and left hepatic ducts. Br J Surg 1998;85:202-207.
3 Vellar ID: The blood supply of the biliary ductal system and its relevance to vasculobiliary injures following cholecystectomy. Aust NZ Surg 1999;69:816-820.

-14 Redman HC, Reuter SR: Arterial collaterals in the liver hilus. Radiology 1970;94:575579.

15 Koehler RE, Korobkin M, Lewis F: Arteriographic demonstration of collateral arterial supply to the liver after hepatic artery ligation. Radiology 1975;117:49-53.

16 Charnsangavej C, Chuang VP, Wallace S, Soo CS, Bowers T: Angiographic classification of hepatic arterial collaterals. Radiology 1982;144:485-494.

17 Tohma T, Cho A, Okazumi S, Makino H, Shuto K, Mochiduki R, Matsubara K, Gunji $\mathrm{H}$, Ochiai T: Communicating arcade between the right and left hepatic arteries: evaluation with CT and angiography during temporary balloon occlusion of the right or left hepatic artery. Radiology 2005;237:361365.

18 Northover JMA, Terblanche J: A new look at the arterial supply of the bile duct in man and its surgical implications. Br J Surg 1979;66: 379-384. 